\title{
Ethics of Energy Technologies
}

Prof. Darryl Macer, Ph.D., Regional Adviser for Social and Human Sciences in Asia and Pacific, RUSHSAP, UNESCO Bangkok

Email: d.macer@unesco.org

The Regional Unit in Social and Human Sciences in Asia and the Pacific (RUSHSAP) at UNESCO Bangkok launched the Ethics of Energy Technologies in Asia and the Pacific Project in September 2007. The launch conference was held also with the cooperation of the Ministry of Energy and Ministry of Science and Technology of Thailand. A full report of that conference is available on the web, as well as the abstracts of the three day meeting, attended by a hundred people from about 20 countries from many sectors and backgrounds. Since then there have been a number of subsequent conferences and working group sessions organized in different countries, and a summary of these will be presented.

Following on from that conference fourteen working groups have been formed on the following topics (more details appear in the project introduction document) [http://www.unescobkk.org/index.php?id=energyethics]:

- Universalism and environmental values

- Ethical worldviews of nature

- Visions and hopes of the future

- Representation and who decides

- Community engagement

- Stakeholder responsibilities

- Energy equity and human security

- Cost-benefit analysis and economic constructions

- Adoption \& development of energy technologies (state of the art review)

- Ethical frameworks for research agendas and policy

- Educational frameworks for environmental ethics

- Nuclear dialogues

- Energy flow, environment, and ethical implications of meat production

- Water ethics and water resource management

The aim of the working groups is to develop dialogue around these particular issues with a focus on environmental ethics and human security. Each group will produce a report with policy options that can be used by policy makers, philosophers, scientists and researchers to consider the ethical dimensions of energy policy. All can follow the report development through the individual websites. The reports will also feed into the COMEST considerations on the ethics of climate change. There are approximately 200 persons who are currently members of the working groups, from young and old, many disciplines, professions and country. This overview will introduce some of the working group results, and progress. More members are invited to join. 